\title{
Reconstruction of periorbital defects using a modified Tenzel flap
}

Jin An Cha, Kyung Ah Lee

Department of Plastic and

Reconstructive Surgery, Inje University

Haeundae Paik Hospital, Busan, Korea
Background: Extensive eyelid defects are extremely challenging to reconstruct. Although numerous procedures for reconstructing periorbital defects have been proposed, no method is universally used. However, the Tenzel flap is the most commonly used technique to reconstruct eyelid defects affecting one-third to two-thirds of the eyelid.

Methods: Recognizing the usefulness of the Tenzel method, we adapted it to reconstruct larger defects around the eyes. Seven patients underwent reconstruction with a modified Tenzel flap with an extended concept after wide excision of a malignant skin lesion. The main difference from the conventional method is that the modified Tenzel flap includes the medial portion of the lower lid defect. The design of a modified Tenzel flap begins as a semicircle at the lateral canthal area, in the same way as a classical Tenzel flap, and extends medially along the subciliary line to cover the defect on the medial lower eyelid. The follow-up time ranged from 3 to 28 months.

Results: All flaps survived and healed well, with minimal scarring and natural palpebral outlines. Conclusion: Compared to traditional procedures, the modified Tenzel flap has several advantages, including a one-stage operation, a less noticeable scar, and effective prevention of complications such as lower eyelid ectropion.

Keywords: Eyelids / Skin neoplasms / Surgical flaps

\section{INTRODUCTION}

Eyelids, which are an integral aesthetic and functional component of the face, are extremely delicate anatomical structures. The goal of procedures performed to reconstruct eyelid defects is to optimize both functional and cosmetic outcomes, which can be challenging for surgeons [1].

Periorbital defects are generally caused by excision of malignant skin tumors, trauma, congenital anomalies, and burns. Of these causes, skin cancer is of particular clinical importance, both because it is the most common cause of eyelid defects and

Correspondence: Kyung Ah Lee

Department of Plastic and Reconstructive Surgery, Inje University College of Medicine, Inje University Haeundae Paik Hospital, 875 Haeun-daero, Haeundaegu, Busan 48108, Korea

E-mail: dlruddk01@naver.com

Received October 4, 2019 / Revised November 19, 2019 / Accepted February 20, 2020 because resection of skin cancer results in a full-thickness defect, the shape of which the surgeon can control through appropriate surgical planning.

Although numerous procedures for reconstructing periorbital defects have been proposed, no method is universally used [211]. A typical surgical plan involves simply covering the defect based on its location and size.

Periorbital defects can be covered with semicircular rotational flaps (Tenzel flaps) [12], vertical myocutaneous cheek-lift flaps [13], Tripier flaps [14], rotation cheek flaps (Mustarde flaps) [15-18], or temporal forehead flaps (Fricke flaps) [19]. The Tenzel advancement flap is the most commonly used technique in eyelid reconstruction procedures following resection of a neoplasm at the eyelid margin and in cases of trauma with fullthickness tissue loss involving approximately one-third to twothirds of the eyelid [20]. 
In light of the usefulness of the Tenzel flap, we modified the original design of the Tenzel flap by adapting it for the reconstruction of larger periorbital defects.

\section{METHODS}

A retrospective review of consecutive patients who underwent periorbital reconstruction with a modified Tenzel flap at Haeundae Paik Hospital from March 2016 to February 2019 was conducted by single surgeon (KAL). To this end, the medical records of 115 patients who were diagnosed with skin cancer were reviewed. Twelve patients had skin cancer in the periorbital area. Four patients were excluded from the study because they had a small defect (involving less than $20 \%$ of the lid), and one patient refused to undergo the flap operation.

Information was collected on patients' age, sex, histopathologic diagnosis of skin cancer, the dimensions of the defect, and complications. The complications assessed included infection, flap necrosis, wound dehiscence, epiphora, ocular irritation, and ectropion.

In all patients, the periorbital defect was reconstructed with a modified Tenzel flap. The indication for a classical Tenzel flap is a full-thickness defect of the central and lateral lower eyelid with coverage between $25 \%$ and $60 \%$ [12,21]. Because classical methods cannot fully cover some periorbital defects, we adapted this flap for the reconstruction of larger defects in the periorbital areas, typically after excision of a malignant skin lesion.

All patients underwent surgery under general anesthesia. Informed consent was obtained for some modified surgical methods before surgery. The area where surgical excision was planned was marked in a round manner (Figs. 1A, 2A). The tumors were excised with adequate oncological safety margins as full-thickness specimens, and then immediately evaluated by frozen-section examinations. Reconstruction was performed after the margins were confirmed to be tumor-free (Fig. 1B).

The design of the modified Tenzel flap begins with a semicircle at the lateral canthal area in the same way as a classical Tenzel flap.

A semicircle is made below Pitanguy line, and a course is tracked between a point $0.5 \mathrm{~cm}$ below the tragus and a point 1.5 $\mathrm{cm}$ above the lateral eyebrow [22]. While maintaining a distance of at least $0.5 \mathrm{~cm}$ from Pitanguy line, the lateral end of the semicircle line is then extended to the level of the tragus until adequate flap mobilization is achieved.

Next, a medial extension is made along the subciliary line, 4 $\mathrm{mm}$ below the cilia. This extension can be adjusted from $2 \mathrm{~mm}$ to $10 \mathrm{~mm}$ depending on the location and size of the defect, and the range can also be adjusted from half the length of the eyelid to the entire length. Through this extension, the lower eyelid subunit can be preserved, yielding more aesthetically pleasing results. A 3- to 4-mm-wide flap is elevated through the subcutaneous plane above the orbicularis muscle, and dissection is then extended to the submuscular plane on the upper cheek area (Figs. 1C, 2B). In other words, this technique reduces the incidence of ectropion by elevating a skin-skin muscle flap, in the form of a stepladder.

As the flap is advanced and rotated into position, the defect is covered without tension. If tension is present, the flap needs to be dissected freely along the superficial musculoaponeurotic system layer towards the cheek. Absorbable polyglactin sutures
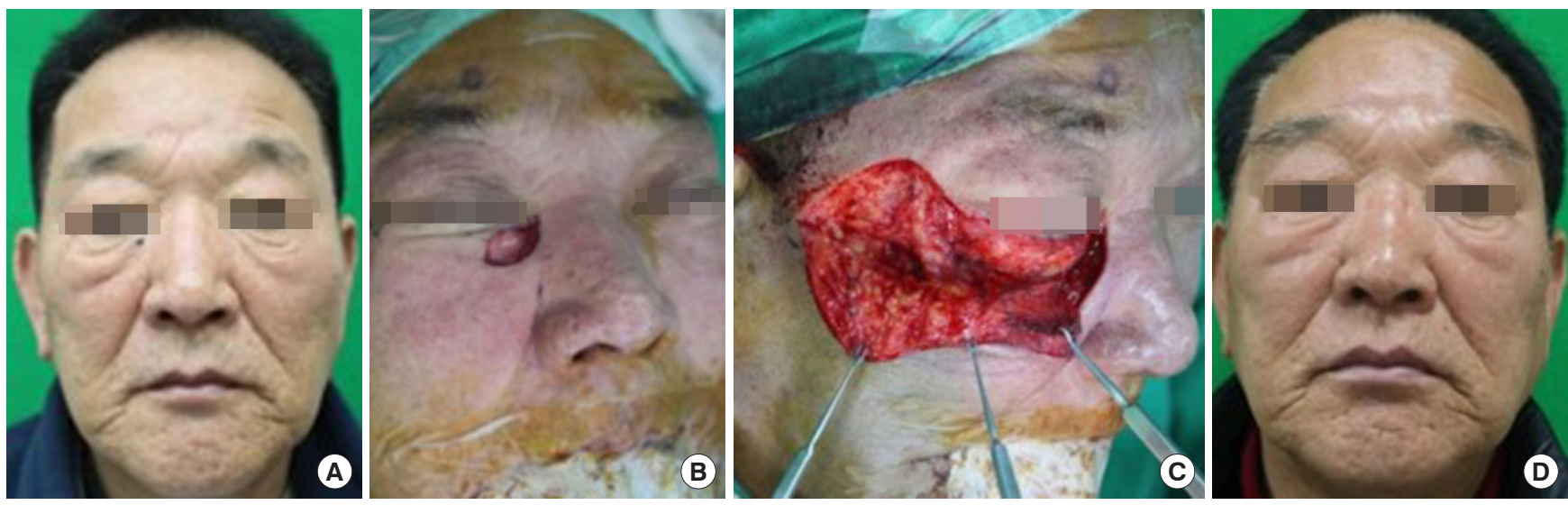

Fig. 1. A 70-year-old man with an $11 \times 6 \mathrm{~mm}$ basal cell carcinoma on the medial side of the eyelid-cheek junction (case 1). (A) Preoperative photograph. (B) Intraoperative photograph showing the defect immediately after excision of the tumor. The defect measured $25 \times 15 \mathrm{~mm}$. (C) Flap elevation began at the superior margin of the flap and proceeded caudally. Superiorly, the plane of elevation was just above that of the orbicularis muscle. Dissection proceeded toward the inferolateral corner of the flap in the subcutaneous plane until sufficient flap mobilization was achieved. (D) The patient's appearance at 20 months after reconstruction. A favorable aesthetic outcome was observed, with a hardly noticeable scar on the lower eyelid and cheek. 

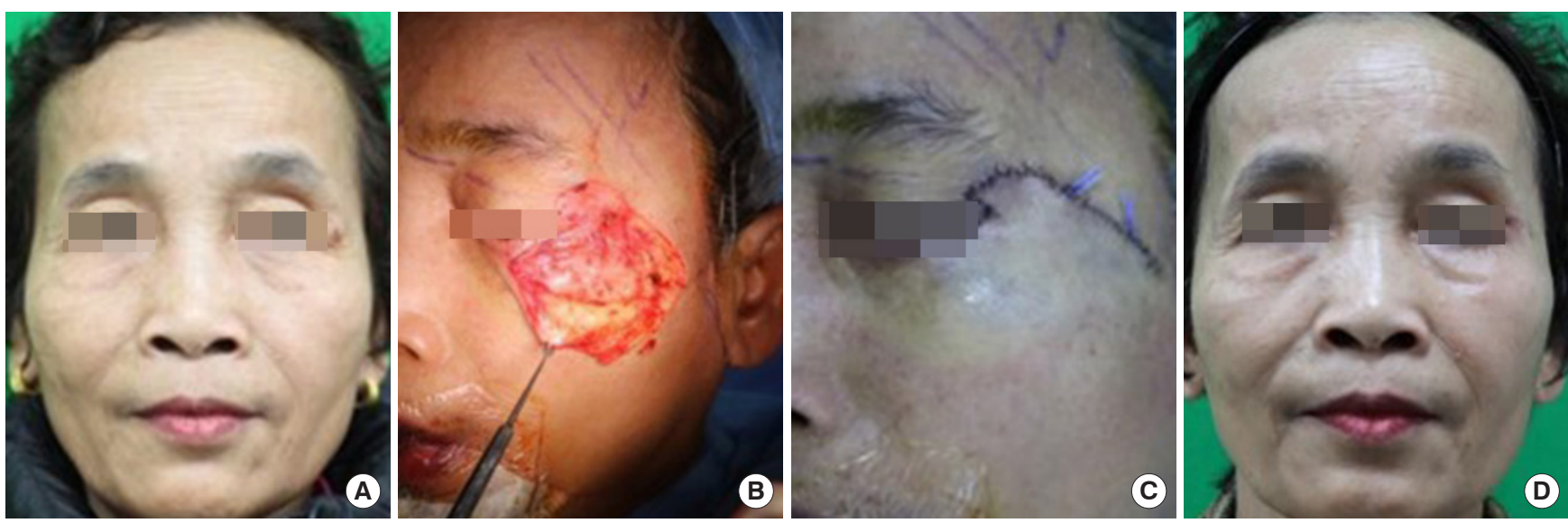

Fig. 2. A 60-year-old woman with a $5 \times 5 \mathrm{~mm}$ basal cell carcinoma on the lateral upper eyelid (case 2). (A) Preoperative photograph. (B) The flap was elevated in the subcutaneous plane and advanced superomedially to close the defect. (C) Immediate postoperative view of the reconstruction using a modified Tenzel flap. (D) Appearance at 3 weeks after reconstruction. An aesthetically gratifying result was observed, with a natural upper lid line.

Table 1. General characteristics of the patients and surgical data

\begin{tabular}{|c|c|c|c|c|c|c|c|}
\hline \multirow{2}{*}{ Case no. } & \multirow{2}{*}{ Sex } & \multirow{2}{*}{ Age (yr) } & \multirow{2}{*}{ Histopathologic diagnosis } & \multicolumn{2}{|c|}{ Dimensions of defect $(\mathrm{mm})$} & \multirow{2}{*}{ Complications } & \multirow{2}{*}{ Follow-up period (mo) } \\
\hline & & & & Width & Height & & \\
\hline 1 & Male & 70 & Basal cell carcinoma & 25 & 12 & None & 28 \\
\hline 2 & Female & 60 & Basal cell carcinoma & 17 & 15 & None & 3 \\
\hline 3 & Male & 69 & Basal cell carcinoma & 13 & 9 & None & 12 \\
\hline 4 & Male & 53 & Basal cell carcinoma & 18 & 12 & None & 7 \\
\hline 5 & Female & 81 & Basal cell carcinoma & 20 & 13 & Epiphora & 3 \\
\hline 6 & Female & 86 & Squamous cell carcinoma & 35 & 25 & None & 3 \\
\hline 7 & Female & 77 & Basal cell carcinoma & 15 & 6 & None & 3 \\
\hline
\end{tabular}

(5-0 and 6-0) are used to stabilize the flap. It is important to secure the advancing flap to a fixed point on the periosteum of orbital rim with a permanent suture to counteract gravitation and to prevent inferior descent of the flap with late ectropion. Skin closure is achieved with simple interrupted or continuous running 6-0 silk sutures (Fig. 2C). A compressive dressing is applied in all cases. Finally, the skin sutures are removed on day 5.

\section{RESULTS}

Seven patients (median age, $70.8 \pm 10.7$ years; median defect size, $301.8 \pm 244.6 \mathrm{~mm}^{2}$ ) underwent surgery using the modified Tenzel advancement flap technique. The median length of follow-up was 8.4 months (range, 3-28 months) (Table 1).

Only one patient complained of ectropion and epiphora, and no other late complications were observed during the course of follow-up. The patient who complained of epiphora and ectropion had a history of lower blepharoplasty. Her symptoms improved after using eye lubricant and receiving regular massages for two months, and no surgical revision was required.
All of the flaps survived and healed well with minimal scarring and natural palpebral outlines (Figs. 1D, 2D). Satisfaction was evaluated using a Likert-type scale. One patient was "very satisfied" with the cosmetic outcome, while the other six patients stated that they were "extremely satisfied."

\section{DISCUSSION}

Approximately 5\% to $10 \%$ of all cases of skin cancer occur in the periorbital area [22]. Basal cell carcinoma, which is the most common type of skin cancer, accounts for roughly $90 \%$ of malignant eyelid tumors [23]. Squamous cell carcinoma is the second most common type of skin cancer, comprising 5\% to $10 \%$ of periorbital tumors, followed by sebaceous carcinoma and melanoma, which are both relatively uncommon [24].

Various surgical methods have been proposed to reconstruct the defects that occur after wide excision of periorbital lesions. Depending on the size of the defect, options include primary closure, a full-thickness skin graft, and local flaps, such as transposition, advancement, and rotation flaps. 
When direct closure is impossible, full-thickness skin grafts were initially considered to be an effective option for periorbital reconstruction because of their procedural simplicity. However, full-thickness skin grafts face certain limitations for large defects, in cases with poor skin color or thickness matches, and in patients with eyelid retraction caused by secondary graft contraction. These limitations have led surgeons to be interested in alternative options.

When another technique is needed instead of a skin graft, a local flap may be the technique of choice for small to moderatesized defects.

The V-Y advancement flap is another option for the reconstruction of periorbital defects. The V-Y advancement flap requires less dissection and less operative time than the cheek flap, and no significant difference was found in the ectropion rate between patients who underwent cervicofacial and V-Y flaps [25-27]. However, the V-Y advancement flap results in a vertical scar across the relaxed skin tension line, causing a poor aesthetic outcome.

A Tripier pedicle flap can be harvested from the upper eyelid and transposed to the lower lid as a unipedicled flap or bipedicled flap [28,29]. However, this procedure has size limitations, particularly in the vertical dimension.

The cheek flap is advantageous because it has good color matching, is well vascularized, and contains an abundance of tissue. This flap can cover large lower lid defects and is most useful for deep vertical defects, especially if the vertical dimension of the defect is greater than the horizontal dimension $[14,18,30]$. However, its rotation direction (inferior to superior) increases the rate of complications such as ectropion and epiphora, and it also leaves a scar at the cheek eminence, which can be conspicuous in Asians.

The Tenzel flap, first described in 1975 [21], is a laterallybased flap that is elevated and rotated to provide sufficient mobilization to repair periorbital defects. Lower lid defects involving up to $60 \%$ of the lid may be closed using a Tenzel flap $[12,21]$. The Tenzel flap can be used to cover moderate-sized defects in a single step that is simple and efficient, and it also has minimal donor site morbidity.

Despite its advantages, the classical Tenzel procedure is not free from cicatricial ectropion. Although the risk of developing lower eyelid ectropion after lower eyelid reconstruction cannot be entirely eliminated, our proposed technique incorporates several steps that minimize this risk. First, flap elevation proceeds along the subcutaneous plane, because some evidence has suggested that ectropion may occur more often when using the deep plane [30-33]. Second, we minimize the inferior tension by recruiting tissue from areas lateral to the defect. Third, suspension sutures are used to anchor the flaps. Specifically, the flap is anchored to the periosteum, typically in the lateral rim, so that all the tension is distributed there.

In the procedure described herein, we adjust the subciliary extension according to the size and location of the lesion. This modification increases the mobility of the flap, without breaking the subunit. This flap can be used to cover small to moderatesized defects on the lower eyelid that involve the pretarsal to lidcheek junction, as well as the lateral half of the upper eyelid. In addition to the defect size, the depth of the defect may be an issue. This flap can even be used to correct deep defects involving the orbicularis oris muscle, with aesthetically favorable results. Our method can serve as a good alternative option for periorbital reconstruction, given the disadvantages of other flaps. For instance, the thick and fatty cheek skin remaining after the cheek flap procedure leaves the patient with an ungainly and plump eyelid that is in sharp contrast to the very thin, distinct skin of the opposite eyelid [34]. Unlike the cheek flap method, the modified Tenzel flap uses ideally colored and textured thin skin for reconstruction, thereby resulting in better outcomes. Moreover, the surgical scars associated with this technique are relatively inconspicuous because they are placed in natural wrinkles and folds, and because the areas involved in the reconstruction procedures heal well in most circumstances. To summarize, we suggest that this technique has the following advantages over the cheek flap: (1) relatively unnoticeable scars, (2) minimal complications such as ectropion or epiphora, and (3) versatile applicability in periorbital reconstruction procedures.

The modified Tenzel flap was shown to have several advantages over traditional procedures. Its principal advantages are its broad applicability, procedural simplicity, less noticeable scars, and effective prevention of complications such as lower eyelid ectropion and distal flap necrosis.

The patients described in this case series who underwent reconstruction with a modified Tenzel flap showed aesthetically and functionally satisfactory outcomes. This flap can thus be considered to be a reliable and useful method for periorbital reconstruction.

\section{NOTES}

\section{Conflict of interest}

No potential conflict of interest relevant to this article was reported.

\section{Ethical approval}

The study was approved by the Institutional Review Board of Inje University Haeundae Paik Hospital (IRB No. 2019-09-028) 
and performed in accordance with the principles of the Declaration of Helsinki. Written informed consents were obtained.

\section{Patient consent}

The patients provided written informed consent for the publication and the use of their images.

\section{ORCID}

Jin An Cha https://orcid.org/0000-0001-5112-9697

Kyung Ah Lee https://orcid.org/0000-0002-3131-1253

\section{REFERENCES}

1. Morley AM, deSousa JL, Selva D, Malhotra R. Techniques of upper eyelid reconstruction. Surv Ophthalmol 2010;55:256-71.

2. Mustarde JC. Repair and reconstruction in the orbital region. 2nd ed. London: Churchill Livingstone; 1971.

3. Hughes WL. A new method for rebuilding a lower lid: report of a case. Arch Opthalmol 1937;17:1008-17.

4. Vayvada H, Menderes A, Tan O, Yilmaz M. Total lower eyelid reconstruction using paranasal flap. J Craniofac Surg 2006;17: 1020-6.

5. Scuderi N, Rubino C. Island chondro-mucosal flap and skin graft: a new technique in eyelid reconstruction. Br J Plast Surg 1994;47:57-9.

6. Zinkernagel MS, Catalano E, Ammann-Rauch D. Free tarsal graft combined with skin transposition flap for full-thickness lower eyelid reconstruction. Ophthalmic Plast Reconstr Surg 2007;23:228-31.

7. Matsumoto K, Nakanishi H, Urano Y, Kubo Y, Nagae H. Lower eyelid reconstruction with a cheek flap supported by fascia lata. Plast Reconstr Surg 1999;103:1650-4.

8. Papp C, Maurer H, Geroldinger E. Lower eyelid reconstruction with the upper eyelid rotation flap. Plast Reconstr Surg 1990; 86:563-5.

9. Heywood AJ, Quaba AA. A cheek island flap for the lower eyelid. Br J Plast Surg 1991;44:183-6.

10. Nakajima T, Yoshimura Y. One-stage reconstruction of fullthickness lower eyelid defects using a subcutaneous pedicle flap lined by a palatal mucosal graft. Br J Plast Surg 1996;49: 183-6.

11. Mehrotra ON. Repairing defects of the lower eyelid with a free chondromucosal graft. Plast Reconstr Surg 1977;59:689-93.

12. Tenzel RR, Stewart WB. Eyelid reconstruction by the semicircle flap technique. Ophthalmology 1978;85:1164-9.

13. McCord CD, Codner MA. Lower eyelid reconstruction. In: McCord CD, Codner MA, editors. Eyelid and periorbital surgery. St. Louis: Quality Medical; 2008. p. 543-76.
14. Tripier L. Musculo-cutaneous flap in the form of a bridge, applied to the reconstruction of the eyelids. Compt Rend Acad SC (Paris) 1889;109:620.

15. Mustarde JC. Eyelid reconstruction. Orbit 1982;1:33-43.

16. Mustarde JC. The use of flaps in the orbital region. Plast Reconstr Surg 1970;45:146-50.

17. Mustarde JC. New horizons in eyelid reconstruction. Int Ophthalmol Clin 1989;29:237-46.

18. Mustarde JC. Reconstruction of eyelids. Ann Plast Surg 1983; 11:149-69.

19. Fricke JCG. Die Bildung neuer Augenlider (Blepharoplastik) nach Zerstorungen und dadurch hervorgebrachten Auswartswendungen derselben. Hamburg: Perthes and Bessler; 1929.

20. Ursula SE, Thomas K. Encyclopedia of ophthalmology. 1st ed. Berlin: Springer; 2018.

21. Tenzel RR. Reconstruction of the central one half of an eyelid. Arch Ophthalmol 1975;93:125-6.

22. Pitanguy I, Ramos AS. The frontal branch of the facial nerve: the importance of its variations in face lifting. Plast Reconstr Surg 1966;38:352-6.

23. Cook BE Jr, Bartley GB. Treatment options and future prospects for the management of eyelid malignancies: an evidencebased update. Ophthalmology 2001;108:2088-98.

24. Welch RB, Duke JR. Lesions of the lids: a statistical note. Am J Ophthalmol 1958;45:415-26.

25. Doermann A, Hauter D, Zook EG, Russell RC. V-Y advancement flaps for tumor excision defects of the eyelids. Ann Plast Surg 1989;22:429-35.

26. Li JH, Xing X, Liu HY, Li P, Xu J. Subcutaneous island pedicle flap: variations and versatility for facial reconstruction. Ann Plast Surg 2006;57:255-9.

27. Sugg KB, Cederna PS, Brown DL. The V-Y advancement flap is equivalent to the Mustardé flap for ectropion prevention in the reconstruction of moderate-size lid-cheek junction defects. Plast Reconstr Surg 2013;131:28e-36e.

28. Alghoul M, Pacella SJ, McClellan WT, Codner MA. Eyelid reconstruction. Plast Reconstr Surg 2013;132:288e-302e.

29. Elliot D, Britto JA. Tripier's innervated myocutaneous flap 1889. Br J Plast Surg 2004;57:543-9.

30. Kroll SS, Reece GP, Robb G, Black J. Deep-plane cervicofacial rotation-advancement flap for reconstruction of large cheek defects. Plast Reconstr Surg 1994;94:88-93.

31. Austen WG Jr, Parrett BM, Taghinia A, Wolfort SF, Upton J. The subcutaneous cervicofacial flap revisited. Ann Plast Surg 2009;62:149-53.

32. Delay E, Lucas R, Jorquera F, Payement G, Foyatier JL. Composite cervicofacial flap for reconstruction of complex cheek defects. Ann Plast Surg 1999;43:347-53. 
33. Becker FF, Langford FP. Deep-plane cervicofacial flap for reconstruction of large cheek defects. Arch Otolaryngol Head Neck Surg 1996;122:997-9.
34. Sullivan SA, Dailey RA. Graft contraction: a comparison of acellular dermis versus hard palate mucosa in lower eyelid surgery. Ophthalmic Plast Reconstr Surg 2003;19:14-24. 